\title{
Analisis Kestabilan Penyebaran Penyakit Kolera Menggunakan Model SEIRS dengan Vaksinasi dan Faktor Treatment
}

\author{
Syafruddin Side ${ }^{1}$, Sukarna $^{1}$, dan Gita Tri Asfarina ${ }^{1, \text { a) }}$ \\ ${ }^{1}$ Jurusan Matematika, Fakultas Matematika dan Ilmu Pengetahuan Alam \\ Universitas Negeri Makassar \\ a) gitaasfarina@gmail.com
}

\begin{abstract}
Abstrak. Pada penelitian ini, tingkat vaksinasi dan tingkat treatment dibandingkan untuk melihat pengaruhnya pada penyebaran penyakit. Diperoleh tingkat vaksinasi minimum dan tingkat treatment minimum yang dibutuhkan agar penyakit dapat menghilang dari populasi. Untuk tingkat vaksinasi dan tingkat treatment di atas vaksinasi minimum dan treatment minimum, semakin besar tingkat vaksinasi dan tingkat treatment menyebabkan proporsi jumlah individu Susceptible semakin kecil, artinya penderita penyakit kolera berangsur-angsur semakin berkurang dan penyakit akan menghilang dari populasi dan tidak terjadi endemik.
\end{abstract}

Kata kunci: model SEIRS, kolera, vaksinasi, treatment.

\begin{abstract}
In this study, the rate of vaccination and treatment than to see the effects on the spread of the disease. In this case, obtained the minimum vaccination and treatment level of the minimum needed for the disease can disappear from the population. For vaccination rates and treatment level above the minimum vaccination and minimum treatment, the greater the rate of vaccination and treatment levels cause the proportion of Susceptible individuals getting smaller, meaning that people with cholera gradually diminishing and the disease will disappear from the population and there is no endemic.
\end{abstract}

Keywords: SEIRS model, cholera, vaccination, treatment

\section{PENDAHULUAN}

Kolera adalah penyakit yang telah lama menyerang manusia dan terus menjadi masalah bagi kesehatan masyarakat dunia (Fitrianah, 2015). Kolera merupakan penyakit infeksi saluran usus bersifat akut yang disebabkan oleh bakteri Vibrio Cholera. Bakteri ini masuk ke dalam tubuh seseorang melalui meminum air atau memakan makanan yang terkontaminasi bakteri Vibrio Cholera. Bakteri ini memproduksi Choleratoxin pada saluran usus sehingga menimbulkan penyakit diare disertai muntah yang akut dan hebat. Akibatnya, seseorang yang dalam waktu beberapa hari akan mengeluarkan cairan tubuh dalam jumlah yang banyak sehingga dapat menyebabkan dehidrasi (Fitrianah, 2015). Kondisi ini merupakan gejala awal penyakit diare akut yang dapat mengakibatkan kematian apabila tidak ditangani dengan cepat dan tepat. Anak-anak lebih banyak yang meninggal akibat penyakit ini, karena mereka lebih cepat mengalami dehidrasi dibandingkan dengan orang dewasa (Renny, 2009).

Kolera menarik perhatian dunia secara global karena berpotensi epidemik dan bahkan pandemik (epidemik yang mendunia). Pandemik ketujuh atau pandemik terakhir, bermula di Indonesia pada 
tahun 1961 kemudian menyebar ke Asia, Afrika, Eropa, dan Amerika Latin hingga tahun 2010 (Fitriyah, 2015).

Pada tahun 2014, WHO melaporkan Afrika adalah benua dengan negara terbanyak tertular penyakit ini. Menurut data yang diperoleh, terdapat sekitar 3-5 juta kasus kolera dan 100-120 ribu di antaranya meninggal setiap tahunnya. Oleh karena kasus kolera yang tiap tahun terus-menerus ada, maka penyakit menular ini tidak bisa diremehkan dan diabaikan (Hidayati, dkk, 2015).

Upaya yang dapat dilakukan untuk menekan penyebaran penyakit kolera adalah dengan memberikan vaksinasi dan melakukan treatment kepada penderita kolera. Vaksinasi dilakukan dengan memberikan vaksin kolera, baik vaksin yang telah dimatikan maupun vaksin hidup yang dilemahkan. Vaksin kolera-CSL (suspensi Vibrio Cholera klasik serotype O1 Inaba dan Ogawa) berasal dari bakteri yang telah dimatikan dengan penambahan fenol 0,5\% sebagai pengawet, bisa melindungi selama beberapa bulan (3-6 bulan). Sedangkan vaksin hidup yang dilemahkan bisa melindungi selama 3 tahun. Treatment terhadap penderita kolera adalah pemberian cairan dan elektrolit secara dini yang dapat menghindarkan terjadinya dehidrasi, bilamana diberikan setelah terjadi dehidrasi maka upaya ini penting untuk memulihkan keseimbangan cairan dan menghindarkan kematian (Lesmana, 2004).

Penelitian terhadap penyakit kolera sudah dilakukan sebelumnya. Renny (2009) yang meneliti tentang model matematika dalam kasus epidemik kolera dengan populasi konstan. Dan penelitian tentang analisa kestabilan untuk penyebaran penyakit kolera berdasarkan model SIR dengan vaksinasi (Hidayati, dkk, 2015). Dalam kedua penelitian tersebut, faktor yang mungkin dapat mempengaruhi penyebaran penyakit tidak diperhatikan dalam model, yaitu faktor treatment.

Oleh karena itu, peneliti ingin melakukan pemodelan penyebaran penyakit kolera dengan model SEIRS dengan memperhatikan faktor vaksinasi dan faktor treatment. Kemudian melakukan analisis di titik kesetimbangan dengan teorema mengenai status penyakit kolera, juga diperoleh model penyebaran penyakit kolera dengan vaksinasi yang diberikan kepada sub kelas populasi yang rentan, serta faktor treatment yang diberikan kepada sub kelas populasi yang terinfeksi sehingga setelah dikontrol tingkat kesembuhan menjadi meningkat, dimana peneliti sebelumnya tidak menunjukkan hal tersebut.

\section{METODE PENELITIAN}

Penelitian yang dilakukan merupakan jenis penelitian murni dengan menggunakan model SEIRS yang bertujuan untuk menganalisis kestabilan di sekitar titik kesetimbangan.

Adapun langkah-langkah yang ditempuh untuk mencapai tujuan penelitian adalah sebagai berikut:

1. Membangun model matematika penyebaran penyakit kolera berdasarkan model SEIRS dengan vaksinasi dan faktor treatment.

2. Menentukan titik kesetimbangan model, yaitu titik kesetimbangan bebas penyakit dan endemik.

3. Menganalisis kestabilan di sekitar titik kesetimbangan model.

4. Mencari bilangan reproduksi dasar, yaitu bilangan reproduksi vaksinasi dan bilangan reproduksi treatment.

5. Menyimpulkan hasil yang diperoleh. 


\section{PEMBAHASAN}

\section{Membangun Model SEIRS dengan Vaksinasi dan Faktor Treatment}

Pada penelitian ini dibahas mengenai pembentukan model SEIRS berdasarkan asumsi yang dibuat. Setelah model terbentuk, kemudian dicari solusi analitis dan titik keseimbangannya, yang selanjutnya diinterpretasikan dalam permasalahan yang sesungguhnya dalam kehidupan nyata. Dalam hal ini adalah mengenai perilaku penyebaran penyakit dan eksistensinya, yaitu titik keseimbangan bebas penyakit dan titik keseimbangan endemik. Penyebaran penyakit dalam suatu populasi diasumsikan memiliki jumlah konstan dan dalam satu periode waktu wabah (t). Populasi dibagi menjadi empat kelas, yaitu kelas Susceptible $(S)$ menyatakan populasi individu yang rentan terkena penyakit, kelas Exposed $(E)$ menyatakan populasi individu yang terdeteksi penyakit tetapi belum terinfeksi, kelas Infected (I) menyatakan populasi individu yang telah terinfeksi penyakit, dan kelas Recovered $(R)$ menyatakan populasi individu yang sembuh dari penyakit, namun tidak memiliki kekebalan terhadap penyakit tersebut, artinya individu akan kembali pada subpopulasi rentan.

Berikut asumsi-asumsi dalam membangun model SEIRS dengan vaksinasi dan faktor treatment:

1. Jumlah populasi dalam setiap subpopulasi dalam suatu periode waktu $t$ adalah $S(t)$, $E(t), I(t)$, dan $R(t)$ dengan proporsi $S(t)+E(t)+I(t)+R(t)=N$.

2. Kematian yang terjadi pada masing-masing kelas Susceptible, Exposed, Infected, maupun Recovered hanya kematian alami.

3. Laju kelahiran dan kematian sama.

4. Populasi kelas individu Susceptible tertular infeksi penyakit kolera, jika terjadi kontak melalui feces populasi kelas individu Infected.

5. Setiap individu yang terdeteksi akan menjadi terinfeksi.

6. Masa inkubasi penyakit kolera 1-4 hari.

7. Treatment diberikan kepada kelas individu Exposed.

8. Populasi individu yang sembuh dari penyakit kolera kembali rentan.

9. Populasi yang lahir pada kelas individu Susceptible, Exposed, Infected, dan Recovered akan rentan terhadap penyakit kolera yang masuk ke dalam kelas Susceptible.

10. Populasi individu yang terinfeksi penyakit kolera dapat sembuh dari penyakit dengan laju kesembuhan $\gamma$.

11. Diasumsikan bahwa vaksin $v$ diberikan setelah terjadi wabah, artinya langsung ada pengendalian dengan vaksinasi. Vaksin $v$ hanya diberikan kepada kelas individu Susceptible.

12. Berdasarkan permasalahan penyebaran penyakit kolera dan asumsi yang diberikan, dapat digambarkan dalam diagram transfer sebagai berikut:

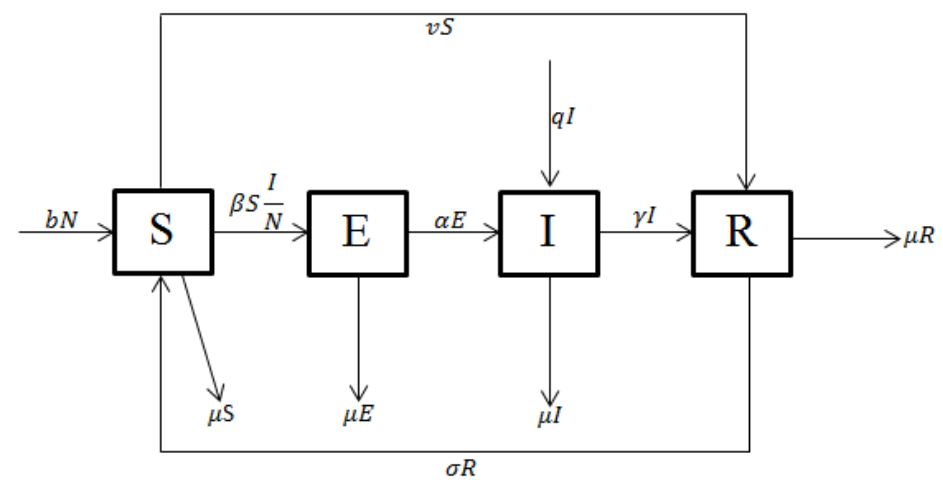

GAMBAR 1 Diagram Transfer Model SEIRS dengan Vaksinasi dan Faktor Treatment 
Berdasarkan Gambar 1, diperoleh model SEIRS dengan vaksinasi dan faktor treatment sebagai berikut:

$$
\begin{gathered}
\frac{d S}{d t}=b N+\sigma R-\beta S \frac{I}{N}-v S-\mu S \\
\frac{d E}{d t}=\beta S \frac{I}{N}-\alpha E-\mu E \\
\frac{d I}{d t}=\alpha E+q I-\gamma I-\mu I \\
\frac{d R}{d t}=\gamma I+v S-\sigma R-\mu R
\end{gathered}
$$

Dengan

$$
\begin{gathered}
S(0)=S_{0} \geq 0, \mathrm{E}(0)=E_{0} \geq 0, \mathrm{I}(0)=I_{0} \geq 0, \mathrm{R}(0)=R_{0} \geq 0, \\
S(t)+E(t)+I(t)+R(t)=N \\
0 \leq v \leq 0.9 .
\end{gathered}
$$

Dimana:

$N \quad$ : jumlah total individu dalam populasi

$b \quad$ : laju kelahiran alami dalam populasi

$\mu \quad$ : laju kematian alami dalam populasi

$\beta \quad$ : laju penularan penyakit

$\alpha \quad$ : laju infektifitas penyakit

$\gamma \quad$ : laju kesembuhan penyakit

$\sigma \quad$ : laju individu yang kembali rentan

$v \quad$ : rasio jumlah individu yang memperoleh vaksin

$q \quad$ : pemberian treatment

\section{Titik Kesetimbangan Model}

Titik kesetimbangan model dapat diperoleh dengan menentukan persamaan (1), (2), (3), dan (4) sama dengan nol. Dengan demikian, persamaan tersebut menjadi:

$$
\begin{gathered}
b N+\sigma R-\beta S \frac{I}{N}-v S-\mu S=0 \\
\beta S \frac{I}{N}-\alpha E-\mu E=0 \\
\alpha E+q I-\gamma I-\mu I=0 \\
\gamma I+v S-\sigma R-\mu R=0
\end{gathered}
$$

Jika $I=0$, maka dari persamaan (5), (6), dan (8) diperoleh:

$$
S=\frac{b N+\sigma R}{(v+\mu)}, E=0, R=\frac{v S}{(\sigma+\mu)}
$$


Jadi, diperoleh titik kesetimbangan bebas penyakit $E_{0}=\left(\frac{b N+\sigma R}{(v+\mu)}, 0,0, \frac{v S}{(\sigma+\mu)}\right)$.

Jika $I \neq 0$, dari persamaan (7) akan diperoleh

$$
E=\frac{(\gamma+\mu-q) I}{\alpha}
$$

Jika persamaan (9) disubtitusikan ke persamaan (6), maka akan diperoleh:

$$
S=\frac{(\alpha+\mu)(\gamma+\mu-q) N}{\alpha \beta}
$$

Subtitusikan persamaan (10) ke persamaan (5), maka akan diperoleh:

$$
I=\frac{\alpha \beta(b N+\sigma R)-(v+\mu)(\alpha+\mu)(\gamma+\mu-q) N}{\beta(\alpha+\mu)(\gamma+\mu-q)}
$$

Subtitusikan persamaan (10) dan (11) ke persamaan (6) dan (8), maka akan diperoleh:

$$
\begin{gathered}
E=\frac{\alpha \beta(b N+\sigma R)-(v+\mu)(\alpha+\mu)(\gamma+\mu-q) N}{\alpha \beta(\alpha+\mu)} \\
R=\left(\frac{(\gamma(\alpha \beta(b N+\sigma R)-(v+\mu)(\alpha+\mu)(\gamma+\mu-q) N))}{\beta(\alpha+\mu)(\gamma+\mu-q)(\sigma+\mu)}\right)+\left(\frac{v((\alpha+\mu)(\gamma+\mu-q) N)}{\alpha \beta(\sigma+\mu)}\right)
\end{gathered}
$$

Jadi, diperoleh titik kesetimbangan endemik $E_{e}=\left(S^{*}, E^{*}, I^{*}, \mathrm{R}^{*}\right)$ dengan $S^{*}=$

$$
\begin{aligned}
& \frac{(\alpha+\mu)(\gamma+\mu-q) N}{\alpha \beta}, E^{*}=\frac{\alpha \beta(b N+\sigma R)-(v+\mu)(\alpha+\mu)(\gamma+\mu-q) N}{\alpha \beta(\alpha+\mu)}, \\
& I^{*}=\frac{\alpha \beta(b N+\sigma R)-(v+\mu)(\alpha+\mu)(\gamma+\mu-q) N}{\beta(\alpha+\mu)(\gamma+\mu-q)}, \text { dan } \\
& R^{*}=\left(\frac{(\gamma(\alpha \beta(b N+\sigma R)-(v+\mu)(\alpha+\mu)(\gamma+\mu-q) N))}{\beta(\alpha+\mu)(\gamma+\mu-q)(\sigma+\mu)}\right)+\left(\frac{v((\alpha+\mu)(\gamma+\mu-q) N)}{\alpha \beta(\sigma+\mu)}\right)
\end{aligned}
$$

\section{Analisis Kestabilan Titik Kesetimbangan}

Analisis kestabilan ditentukan berdasarkan nilai eigen dan matriks Jacobian yang diperoleh dari metode linearisasi.

Kestabilan di Titik Kesetimbangan Bebas Penyakit $\left(E_{0}\right)$

Matriks Jacobian di persekitaran $E_{0}$ adalah: 


$$
J_{0}=\left[\begin{array}{cccc}
-v-\mu & 0 & -\frac{\beta(b+\sigma R)}{(v+\mu)} & \sigma \\
0 & -\alpha-\mu & \frac{\beta(b+\sigma R)}{(v+\mu)} & 0 \\
0 & \alpha & q-\gamma-\mu & 0 \\
v & 0 & \gamma & -\sigma-\mu
\end{array}\right]
$$

Persamaan karakteristiknya adalah $\left|J_{0}-\lambda I\right|=0$

$$
\begin{aligned}
& \Leftrightarrow\left[\begin{array}{cccc}
-v-\mu & 0 & -\frac{\beta(b+\sigma R)}{(v+\mu)} & \sigma \\
0 & -\alpha-\mu & \frac{\beta(b+\sigma R)}{(v+\mu)} & 0 \\
0 & \alpha & q-\gamma-\mu & 0 \\
v & 0 & \gamma & -\sigma-\mu
\end{array}\right]-\left[\begin{array}{cccc}
\lambda & 0 & 0 & 0 \\
0 & \lambda & 0 & 0 \\
0 & 0 & \lambda & 0 \\
0 & 0 & 0 & \lambda
\end{array}\right]=0 \\
& \left.\Leftrightarrow \mid \begin{array}{cccc}
-v-\mu-\lambda & 0 & -\frac{\beta(b+\sigma R)}{(v+\mu)} & \sigma \\
0 & -\alpha-\mu-\lambda & \frac{\beta(b+\sigma R)}{(v+\mu)} & 0 \\
0 & \alpha & q-\gamma-\mu-\lambda & 0 \\
v & 0 & \gamma & -\sigma-\mu-\lambda
\end{array}\right] \mid=0 \\
& \left.\Leftrightarrow(-v-\mu-\lambda)\left((-\alpha-\mu-\lambda) \mid \begin{array}{cc}
q-\gamma-\mu-\lambda & 0 \\
\gamma & -\sigma-\mu-\lambda
\end{array}\right]\left|-\left(\frac{\beta(b+\sigma R)}{(v+\mu)}\right)\left[\begin{array}{cc}
\alpha & 0 \\
0 & -\sigma-\mu-\lambda
\end{array}\right]\right|\right)-(v)\left((\sigma) \mid\left[\begin{array}{cc}
-\alpha-\mu-\lambda & \frac{\beta(b+\sigma R)}{(v+\mu)} \\
\alpha & q-\gamma-\mu-\lambda
\end{array}\right]\right)=0 \\
& \Leftrightarrow(-v-\mu-\lambda)\left((-\alpha-\mu-\lambda)[(q-\gamma-\mu-\lambda)(-\sigma-\mu-\lambda)]-\left(\frac{\beta(b+\sigma R)}{(v+\mu)}\right)[(\alpha)(-\sigma-\mu-\lambda)]\right) \\
& -(v)\left((\sigma)\left[(-\alpha-\mu-\lambda)(q-\gamma-\mu-\lambda)-(\alpha)\left(\frac{\beta(b+\sigma R)}{(v+\mu)}\right)\right]\right)=0 \\
& \Leftrightarrow((-v-\mu-\lambda)(-\sigma-\mu-\lambda)-(v)(\sigma))\left((-\alpha-\mu-\lambda)(q-\gamma-\mu-\lambda)-\left(\frac{\beta(b+\sigma R)}{(v+\mu)}\right)(\alpha)\right)=0
\end{aligned}
$$

Jadi, ada dua kemungkinan untuk menentukan nilai eigen, yaitu:

$$
((-v-\mu-\lambda)(-\sigma-\mu-\lambda)-(v)(\sigma))=0
$$

Diketahui persamaan karakteristik $\lambda^{2}+(2 \mu+\sigma+v) \lambda+\mu(v+\sigma+\mu)=0$

Dimisalkan:

$$
\lambda^{2}+A \lambda+B=0
$$


Berdasarkan persamaan karakteristik (14), maka diperoleh:

$$
\begin{aligned}
& A=(2 \mu+\sigma+v) \\
& B=\mu(v+\sigma+\mu)
\end{aligned}
$$

Karena $\mu, \sigma, v>0$, maka $(2 \mu+\sigma+v)=A>0$ dan $\mu(v+\sigma+\mu)=B>0$.

Berdasarkan nilai koefisien persamaan $Q(\lambda)$, diperoleh:

$$
h_{0}=1, h_{1}=A, h_{2}=B
$$

dibentuk matriks Hurwitz berikut:

$$
H=\left[\begin{array}{ll}
h_{1} & h_{3} \\
h_{0} & h_{2}
\end{array}\right]=\left[\begin{array}{ll}
A & 0 \\
1 & B
\end{array}\right]
$$

Berdasarkan matriks Hurwitz di atas, diperoleh determinan Hurwitz:

$$
\begin{aligned}
& \Delta_{1}=\left|h_{1}\right|=|A|=A \\
& \Delta_{2}=\left|\begin{array}{ll}
h_{1} & h_{3} \\
h_{0} & h_{2}
\end{array}\right|=\left|\begin{array}{ll}
A & 0 \\
1 & B
\end{array}\right|=A B
\end{aligned}
$$

dari nilai $A$ dan $B$, maka dapat diketahui bahwa:

- $A>0 \Rightarrow \Delta_{1}=A>0$

- $A>0, B>0$, maka $A B>0 \Rightarrow \Delta_{2}=A B>0$

$$
\left((-\alpha-\mu-\lambda)(q-\gamma-\mu-\lambda)-\left(\frac{\beta(b+\sigma R)}{(v+\mu)}\right)(\alpha)\right)=0
$$

Diketahui persamaan karakteristik

$$
\lambda^{2}+(2 \mu+\alpha+\gamma-q) \lambda+(\mu+\alpha)\left((\mu+\gamma-q)-\left(\frac{\beta(b+\sigma R)}{(v+\mu)}\right)\right)=0
$$

Dimisalkan:

$$
\lambda^{2}+A \lambda+B=0
$$

berdasarkan persamaan karakteristik (15), maka diperoleh:

$$
\begin{aligned}
& A=(2 \mu+\alpha+\gamma-q) \\
& B=(\mu+\alpha)\left((\mu+\gamma-q)-\left(\frac{\beta(b+\sigma R)}{(v+\mu)}\right)\right)
\end{aligned}
$$

Karena $\quad \mu, \alpha, \gamma, q, \beta, b, \sigma, v>0, \quad$ maka $\quad(2 \mu+\alpha+\gamma-q)=A>0 \quad$ dan $(\mu+\alpha)\left((\mu+\gamma-q)-\left(\frac{\beta(b+\sigma R)}{(v+\mu)}\right)\right)=B>0$

Berdasarkan nilai koefisien persamaan $Q(\lambda)$, diperoleh:

$$
h_{0}=1, h_{1}=A, h_{2}=B
$$


dibentuk matriks Hurwitz berikut:

$$
H=\left[\begin{array}{ll}
h_{1} & h_{3} \\
h_{0} & h_{2}
\end{array}\right]=\left[\begin{array}{ll}
A & 0 \\
1 & B
\end{array}\right]
$$

Berdasarkan matriks Hurwitz di atas, diperoleh determinan Hurwitz:

$$
\begin{aligned}
& \Delta_{3}=\left|h_{1}\right|=|A|=A \\
& \Delta_{4}=\left|\begin{array}{ll}
h_{1} & h_{3} \\
h_{0} & h_{2}
\end{array}\right|=\left|\begin{array}{ll}
A & 0 \\
1 & B
\end{array}\right|=A B
\end{aligned}
$$

dari nilai $A$ dan $B$, maka dapat diketahui bahwa:

- $A>0 \Rightarrow \Delta_{3}=A>0$

- $A>0, B>0$, maka $A B>0 \Rightarrow \Delta_{4}=A B>0$

Karena nilai $\Delta_{1}>0, \Delta_{2}>0, \Delta_{3}>0$, dan $\Delta_{4}>0$ maka polinomial $Q(\lambda)$ mempunyai pembuat nol yang bagian realnya negatif. Dengan demikian, semua bilangan real nilai eigen pada matriks $J_{0}$ bernilai negatif. Berdasarkan Kriteria Routh-Hurwitz, jika determinan Hurwitz adalah positif, maka semua akar-akar dari persamaan polinomial $Q(\lambda)$ adalah negatif atau mempunyai bagian real yang negatif. Dengan kata lain, nilai eigen $\lambda_{(1,2,3,4)}$ mempunyai bagian real negatif. Sehingga dapat disimpulkan bahwa sistem di sekitar titik kesetimbangan bebas penyakit $E_{0}$ stabil asimtotik lokal. Hal ini menunjukkan bahwa dalam jangka waktu yang lama, individu yang ada di dalam populasi menuju titik $E_{0}$ atau tidak ada individu yang terinfeksi penyakit.

Kestabilan di Titik Kesetimbangan Endemik $\left(E_{e}\right)$

Matriks Jacobian di persekitaran $E_{e}$ adalah:

$$
J_{1}=\left[\begin{array}{cccc}
-\beta \frac{I^{*}}{N}-v-\mu & 0 & -\beta \frac{S^{*}}{N} & \sigma \\
\beta \frac{I^{*}}{N} & -\alpha-\mu & \beta \frac{S^{*}}{N} & 0 \\
0 & \alpha & q-\gamma-\mu & 0 \\
v & 0 & \gamma & -\sigma-\mu
\end{array}\right]
$$

Persamaan karakteristiknya adalah $\left|J_{0}-\lambda I\right|=0$

$$
\left.\Leftrightarrow \mid \begin{array}{cccc}
-\beta \frac{I^{*}}{N}-v-\mu & 0 & -\beta \frac{S^{*}}{N} & \sigma \\
\beta \frac{I^{*}}{N} & -\alpha-\mu & \beta \frac{S^{*}}{N} & 0 \\
0 & \alpha & q-\gamma-\mu & 0 \\
v & 0 & \gamma & -\sigma-\mu
\end{array}\right]-\left[\begin{array}{cccc}
\lambda & 0 & 0 & 0 \\
0 & \lambda & 0 & 0 \\
0 & 0 & \lambda & 0 \\
0 & 0 & 0 & \lambda
\end{array}\right]=0
$$




$$
\left.\Leftrightarrow \mid \begin{array}{cccc}
-\beta \frac{I^{*}}{N}-v-\mu-\lambda & 0 & -\beta \frac{S^{*}}{N} & \sigma \\
\beta \frac{I^{*}}{N} & -\alpha-\mu-\lambda & \beta \frac{S^{*}}{N} & 0 \\
0 & \alpha & q-\gamma-\mu-\lambda & 0 \\
v & 0 & \gamma & -\sigma-\mu-\lambda
\end{array}\right] \mid=0
$$

Persamaan karakteristik diperoleh:

$$
\begin{aligned}
& \lambda^{4}+\left(1+4 \mu+\sigma+\gamma+v+\alpha+\beta \frac{I^{*}}{N}-q\right) \lambda^{3}
\end{aligned}
$$

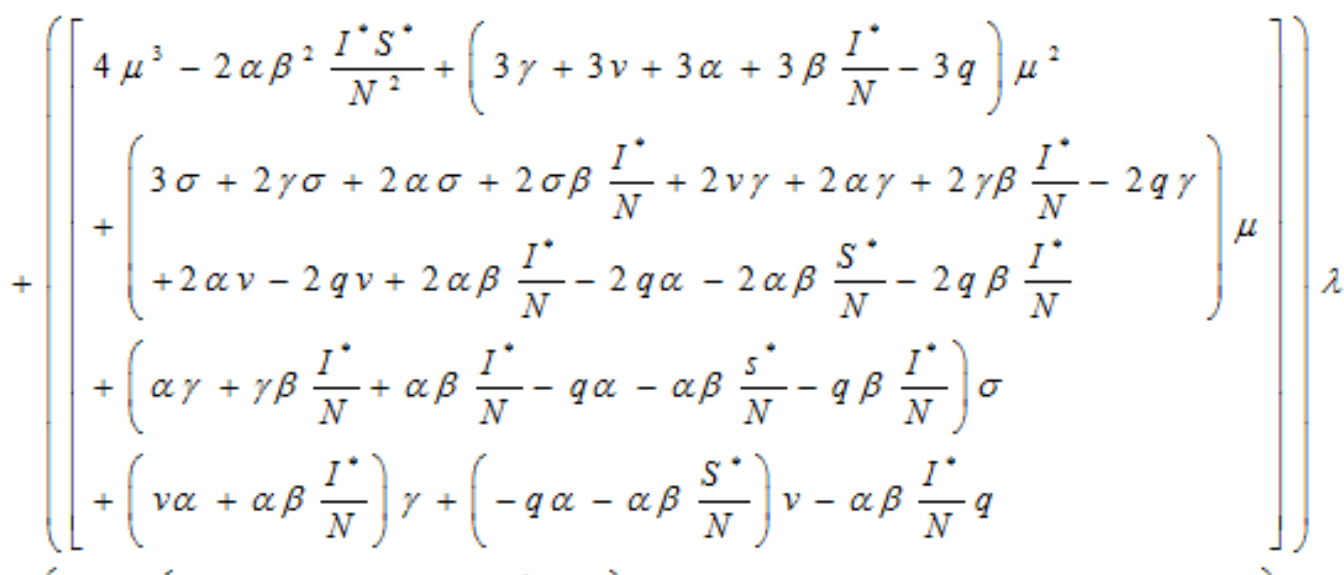

$$
\begin{aligned}
& +\left(\begin{array}{l}
\mu^{4}+\left(\sigma+\gamma+v+\alpha+\beta \frac{I^{*}}{N}-q\right) \mu^{3}+ \\
\left.\gamma \sigma+\alpha \sigma+\beta \frac{I^{*}}{N} \sigma-q \sigma+v \gamma+\alpha \gamma+\beta \frac{I^{*}}{N} \gamma+\alpha v-q v+\alpha \beta \frac{I^{*}}{N}\right) \mu^{2} \\
-q \alpha-\alpha \beta \frac{S^{*}}{N}-\beta \frac{I^{*}}{N} q \\
+\left(\begin{array}{l}
\gamma \alpha \sigma+\beta \frac{I^{*}}{N} \gamma \sigma+\alpha \beta \frac{I^{*}}{N} \sigma-\alpha q \sigma-\beta \frac{I^{*}}{N} q \sigma-\alpha \beta \frac{S^{*}}{N} \sigma+v \alpha \gamma \\
+\alpha \beta \frac{I^{*}}{N} \gamma-\alpha q v-\alpha \beta \frac{S^{*}}{N} v-2 \alpha \beta^{2} \frac{I^{*} S^{*}}{N^{2}}-\alpha \beta \frac{I^{*}}{N} q \\
+\left(2 \alpha \beta \frac{I^{*}}{N} \gamma-\alpha \beta \frac{I^{*}}{N} q-\alpha \beta^{2} \frac{I^{*} S^{*}}{N^{2}}\right) \sigma-\alpha \beta^{2} \frac{I^{*} S^{*}}{N^{2}} \gamma
\end{array}\right) \mu
\end{array}\right)=0
\end{aligned}
$$

Dimisalkan:

$$
\lambda^{4}+A \lambda^{3}+B \lambda^{2}+C \lambda+D=0
$$

dengan:

$$
A=\left(1+4 \mu+\sigma+\gamma+v+\alpha+\beta \frac{I^{*}}{N}-q\right)>0
$$




$$
\begin{aligned}
& B=\left(\left[\begin{array}{l}
6 \mu^{2}+\left(3 \sigma+3 \gamma+3 v+3 \alpha+3 \beta \frac{I^{*}}{N}-3 q\right) \mu+\left(\gamma+\alpha+\beta \frac{I^{*}}{N}-q\right) \sigma \\
+\left(v+\alpha+\beta \frac{I^{*}}{N}\right) \gamma+(\alpha-q) v+\left(\beta \frac{I^{*}}{N}-q-\beta \frac{S^{*}}{N}\right) \alpha-\beta \frac{I^{*}}{N} q
\end{array}\right]\right)>0 \\
& C=\left(\left[\begin{array}{l}
4 \mu^{3}-2 \alpha \beta^{2} \frac{I^{*} S^{*}}{N^{2}}+\left(3 \gamma+3 v+3 \alpha+3 \beta \frac{I^{*}}{N}-3 q\right) \mu^{2} \\
+\left(\begin{array}{l}
3 \sigma+2 \gamma \sigma+2 \alpha \sigma+2 \sigma \beta \frac{I^{*}}{N}+2 v \gamma+2 \alpha \gamma+2 \gamma \beta \frac{I^{*}}{N}-2 q \gamma \\
+2 \alpha v-2 q v+2 \alpha \beta \frac{I^{*}}{N}-2 q \alpha-2 \alpha \beta \frac{S^{*}}{N}-2 q \beta \frac{I^{*}}{N}
\end{array}\right] \mu \\
+\left(\alpha \gamma+\gamma \beta \frac{I^{*}}{N}+\alpha \beta \frac{I^{*}}{N}-q \alpha-\alpha \beta \frac{s^{*}}{N}-q \beta \frac{I^{*}}{N}\right) \sigma \\
+\left(v \alpha+\alpha \beta \frac{I^{*}}{N}\right) \gamma+\left(-q \alpha-\alpha \beta \frac{S^{*}}{N}\right) v-\alpha \beta \frac{I^{*}}{N} q
\end{array}\right]\right)>0 \\
& D=\left(\begin{array}{l}
\mu^{4}+\left(\sigma+\gamma+v+\alpha+\beta \frac{I^{*}}{N}-q\right) \mu^{3}+ \\
\left(\begin{array}{l}
\gamma \sigma+\alpha \sigma+\beta \frac{I^{*}}{N} \sigma-q \sigma+v \gamma+\alpha \gamma+\beta \frac{I^{*}}{N} \gamma+\alpha v-q v+\alpha \beta \frac{I^{*}}{N} \\
-q \alpha-\alpha \beta \frac{S^{*}}{N}-\beta \frac{I^{*}}{N} q
\end{array}\right) \mu^{2} \\
+\left(\begin{array}{l}
\gamma \alpha \sigma+\beta \frac{I^{*}}{N} \gamma \sigma+\alpha \beta \frac{I^{*}}{N} \sigma-\alpha q \sigma-\beta \frac{I^{*}}{N} q \sigma-\alpha \beta \frac{S^{*}}{N} \sigma+v \alpha \gamma \\
+\alpha \beta \frac{I^{*}}{N} \gamma-\alpha q v-\alpha \beta \frac{S^{*}}{N} v-2 \alpha \beta^{2} \frac{I^{*} S^{*}}{N^{2}}-\alpha \beta \frac{I^{*}}{N} q \\
+\left(2 \alpha \beta \frac{I^{*}}{N} \gamma-\alpha \beta \frac{I^{*}}{N} q-\alpha \beta^{2} \frac{I^{*} S^{*}}{N^{2}}\right) \sigma-\alpha \beta^{2} \frac{I^{*} S^{*}}{N^{2}} \gamma
\end{array}\right) \mu
\end{array}\right)>0
\end{aligned}
$$

Berdasarkan nilai polinomial $Q(\lambda)$, diperoleh:

$$
h_{0}=1, h_{1}=A, h_{2}=B, h_{3}=C, h_{4}=D
$$

dibentuk matriks Hurwitz berikut:

$$
H=\left[\begin{array}{llll}
h_{1} & h_{0} & 0 & 0 \\
h_{3} & h_{2} & h_{1} & h_{0} \\
h_{5} & h_{4} & h_{3} & h_{2} \\
h_{7} & h_{6} & h_{5} & h_{4}
\end{array}\right]=\left[\begin{array}{cccc}
A & 1 & 0 & 0 \\
C & B & A & 1 \\
0 & D & C & B \\
0 & 0 & 0 & D
\end{array}\right]
$$

Berdasarkan matriks Hurwitz di atas, diperoleh determinan Hurwitz: 


$$
\begin{aligned}
& \Delta_{1}=\left|h_{1}\right|=|A|=A \\
& \Delta_{2}=\left|\begin{array}{ll}
h_{1} & h_{0} \\
h_{3} & h_{2}
\end{array}\right|=\left|\begin{array}{ll}
A & 1 \\
C & B
\end{array}\right|=A B-C \\
& \Delta_{3}=\left|\begin{array}{lll}
h_{1} & h_{0} & 0 \\
h_{3} & h_{2} & h_{1} \\
h_{5} & h_{4} & h_{3}
\end{array}\right|=\left|\begin{array}{ccc}
A & 1 & 0 \\
C & B & A \\
0 & D & C
\end{array}\right|=A B C-\left(D A^{2}+C^{2}\right) \\
& \Delta_{4}=\left[\begin{array}{llll}
h_{1} & h_{0} & 0 & 0 \\
h_{3} & h_{2} & h_{1} & h_{0} \\
h_{5} & h_{4} & h_{3} & h_{2} \\
h_{7} & h_{6} & h_{5} & h_{4}
\end{array}\right]=\left[\begin{array}{cccc}
A & 1 & 0 & 0 \\
C & B & A & 1 \\
0 & D & C & B \\
0 & 0 & 0 & D
\end{array}\right]=A\left(B C D-D^{2} A\right)-C(C D)
\end{aligned}
$$

dari nilai $A, B, C$, dan $D$ maka dapat diketahui bahwa:

- $A>0 \Rightarrow \Delta_{1}=A>0$

- $A>0, B>0, C>0, A>B>C$, maka $A B>C \rightarrow \Delta_{2}=A B-C>0$

- $A>0, B>0, C>0, D>0, A>B>C>D$,

$$
\text { maka } A B C>D \Rightarrow \Delta_{3}=A B C-\left(D A^{2}+C^{2}\right)>0
$$

- $A>0, B>0, C>0, D>0, A>B>C>D \Rightarrow \Delta_{4}=A\left(B C D-D^{2} A\right)-C(C D)>0$

Karena nilai $\Delta_{1}>0, \Delta_{2}>0, \Delta_{3}>0$, dan $\Delta_{4}>0$ maka polinomial $Q(\lambda)$ mempunyai pembuat nol yang bagian realnya negatif. Dengan demikian, semua bilangan real nilai eigen pada matriks $J_{1}$ bernilai negatif. Berdasarkan Kriteria Routh-Hurwitz, jika determinan Hurwitz adalah positif, maka semua akar-akar dari persamaan polinomial $Q(\lambda)$ adalah negatif atau mempunyai bagian real yang negatif. Sehingga dapat disimpulkan bahwa sistem di sekitar titik kesetimbangan endemik $E_{e}=\left(S^{*}, E^{*}, I^{*}, R^{*}\right)$ stabil asimtotik lokal. Hal ini menunjukkan bahwa dalam jangka waktu yang lama, individu yang ada di dalam populasi menuju titik $E_{e}$ atau masih ada individu yang terinfeksi penyakit kolera.

\section{Bilangan Reproduksi Dasar}

Untuk mengetahui tingkat penyebaran suatu penyakit diperlukan suatu parameter. Parameter yang biasa digunakan dalam masalah penyebaran penyakit adalah bilangan reproduksi. Bilangan reproduksi yang digunakan dalam penelitian ini adalah bilangan reproduksi vaksinasi dan bilangan reproduksi treatment.

Bilangan reproduksi vaksinasi dan bilangan reproduksi treatment diperoleh dengan menggunakan bilangan konstanta pada persamaan karakteristik dari kestabilan titik kesetimbangan bebas penyakit.

$$
\Rightarrow(\mu(v+\sigma+\mu))\left((\mu+\alpha)\left[(\mu+\gamma-q)-\left(\frac{\beta(b+\sigma R)}{(v+\mu)}\right)\right]\right)>0
$$




$$
\begin{gathered}
\Rightarrow \frac{\mu(v+\sigma+\mu)(\mu+\alpha)(\mu+\gamma-q)}{\mu(v+\sigma+\mu)(\mu+\alpha)\left(\frac{\beta(b+\sigma R)}{(v+\mu)}\right)}<1 \\
\Rightarrow \frac{(\mu+\gamma-q)(v+\mu)}{\beta(b+\sigma R)}<1
\end{gathered}
$$

Berdasarkan persamaan (17), rasio bilangan reproduksi vaksinasi dan treatment sebagai berikut:

$$
R_{0}=\frac{(\mu+\gamma-q)(v+\mu)}{\beta(b+\sigma R)}
$$

Jika $R_{0}<1$ artinya penyakit akan menghilang dari populasi dan jika $R_{0}>1$ artinya infeksi akan menuju tak hingga.

Untuk $R_{0}=1$ diperoleh tingkat vaksinasi minimum dan tingkat treatment minimum, yaitu:

$$
\begin{gathered}
v_{m}=\mu-\frac{\beta(b+\sigma R)}{(\mu+\gamma-q)} \\
q_{m}=\mu+\gamma-\frac{\beta(b+\sigma R)}{(v+\mu)}
\end{gathered}
$$

Jika tingkat vaksinasi yang diberikan lebih dari tingkat vaksinasi minimum $v_{m}$, maka:

$$
\begin{aligned}
& \frac{(\mu+\gamma-q)(v+\mu)}{\beta(b+\sigma R)}<\frac{(\mu+\gamma-q)\left(v_{m}+\mu\right)}{\beta(b+\sigma R)} \\
& R_{0}(v)<R_{0}\left(v_{m}\right)=1
\end{aligned}
$$

Jika tingkat vaksinasi yang diberikan kurang dari tingkat vaksinasi minimum $v_{m}$, maka:

$$
\begin{aligned}
& \frac{(\mu+\gamma-q)(v+\mu)}{\beta(b+\sigma R)}>\frac{(\mu+\gamma-q)\left(v_{m}+\mu\right)}{\beta(b+\sigma R)} \\
& R_{0}(v)>R_{0}\left(v_{m}\right)=1
\end{aligned}
$$

Jika tingkat treatment yang diberikan lebih dari tingkat treatment minimum $q_{m}$, maka:

$$
\begin{aligned}
& \frac{(\mu+\gamma-q)(v+\mu)}{\beta(b+\sigma R)}<\frac{\left(\mu+\gamma-q_{m}\right)(v+\mu)}{\beta(b+\sigma R)} \\
& R_{0}(q)<R_{0}\left(q_{m}\right)=1
\end{aligned}
$$

Jika tingkat treatment yang diberikan kurang dari tingkat treatment minimum $q_{m}$, maka:

$$
\begin{aligned}
& \frac{(\mu+\gamma-q)(v+\mu)}{\beta(b+\sigma R)}>\frac{\left(\mu+\gamma-q_{m}\right)(v+\mu)}{\beta(b+\sigma R)} \\
& R_{0}(q)>R_{0}\left(q_{m}\right)=1
\end{aligned}
$$




\section{KESIMPULAN DAN SARAN}

\section{Kesimpulan}

1. Diperoleh model matematika analisis kestabilan penyebaran penyakit kolera dengan vaksinasi dan faktor treatment sebagai berikut:

$$
\begin{aligned}
& \frac{d S}{d t}=b N+\sigma R-\beta S \frac{I}{N}-v S-\mu S \\
& \frac{d E}{d t}=\beta S \frac{I}{N}-\alpha E-\mu E \\
& \frac{d I}{d t}=\alpha E+q I-\gamma I-\mu I \\
& \frac{d R}{d t}=\gamma I+v S-\sigma R-\mu R
\end{aligned}
$$

2. Diperoleh dua titik kesetimbangan, yaitu titik kesetimbangan bebas penyakit $E_{0}=\left(\frac{b N+\sigma R}{(v+\mu)}, 0,0, \frac{v S}{(\sigma+\mu)}\right)$ dan titik kesetimbangan endemik

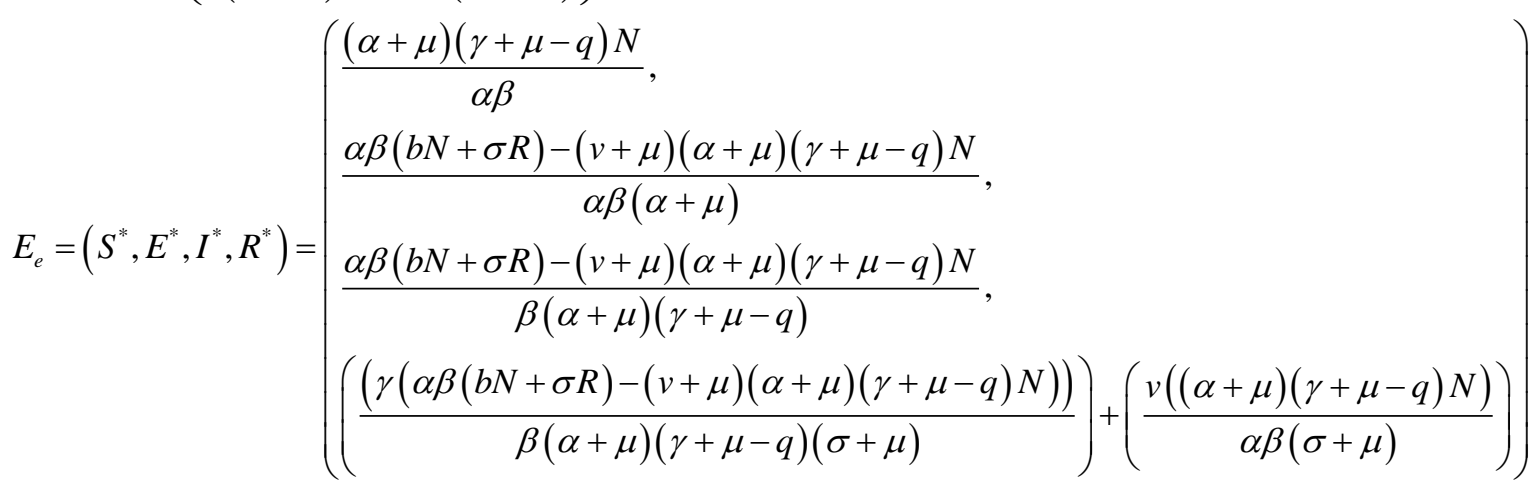

3. Berdasarkan Kriteria Routh-Hurwitz, titik kesetimbangan bebas penyakit $E_{0}$ dan titik kesetimbangan endemik $E_{e}$ adalah stabil asimtotik lokal.

4. Berdasarkan bilangan reproduksi vaksinasi, jika $R_{0}<1$ maka jumlah penderita penyakit kolera berangsur-angsur semakin berkurang sehingga penyakit akan menghilang dari populasi dan tidak terjadi endemik. Jika $R_{0}>1$ maka jumlah penderita penyakit kolera berangsur-angsur semakin bertambah sehingga penyakit meluas dan menjadi endemik. Agar jumlah penderita penyakit kolera dapat ditekan sekecil mungkin dan penyakit dapat menghilang dari populasi, tingkat vaksinasi yang diberikan harus lebih dari tingkat vaksinasi minimum.

5. Berdasarkan bilangan reproduksi treatment, jika $R_{0}<1$ maka jumlah penderita penyakit kolera berangsur-angsur akan sembuh dan semakin berkurang sehingga penyakit akan menghilang dari populasi dan tidak terjadi endemik. Jika $R_{0}>1$ maka jumlah penderita penyakit kolera berangsur-angsur semakin bertambah sehingga penyakit meluas dan menjadi endemik. Agar tingkat kesembuhan penderita penyakit kolera meningkat dan penyakit dapat menghilang dari populasi, tingkat treatment yang diberikan harus lebih dari tingkat treatment minimum. 


\section{Saran}

1. Dalam penulisan tugas akhir ini, penulis membahas model penyebaran penyakit dengan menggunakan model matematika SEIRS yang memperhatikan faktor vaksinasi dan treatment, masih banyak faktor-faktor yang perlu diperhatikan dalam model namun tidak dibahas dalam penelitian ini, seperti biaya vaksinasi, biaya treatment, imigrasi, laju kelahiran yang tidak sama dengan laju kematian. dan lain-lain. Oleh karena itu, untuk penelitian selanjutnya disarankan mengembangkan model SEIRS ini dengan memperhatikan faktor-faktor lainnya yang mungkin dapat mempengaruhi model penyebaran, dapat pula mengembangkan penelitian ini dengan menggunakan modelmodel penyebaran penyakit lainnya seperti model matematika SEIR, SIS, atau SIRS, dalam rangka melengkapi model penyebaran penyakit yang telah dilakukan peneliti sebelumnya.

2. Sebaiknya, sebelum melakukan penelitian sekiranya peneliti dapat mencari tahu terlebih dahulu mengenai ada atau tidak adanya data yang akan digunakan dalam penelitian, sehingga akan lebih memudahkan ketika melakukan suatu penelitian.

\section{DAFTAR PUSTAKA}

Fitrianah, A. (2015). Vibrio Cholerae. Medan: Departemen Mikrobiologi Fakultas Kedokteran Universitas Sumatera Utara.

Renny. 2009. Model Matematika dalam Kasus Epidemik Kolera dengan Populasi Konstan. Universitas Jenderal Sudirman, Purwokerto.

Fitriyah, Aini. 2015. Suatu Analisis dari Model Matematika Penyakit Kolera (Tesis). Universitas Gajah Mada, Yogyakarta.

Hidayati, Noer, dkk.. 2015. Analisis Kestabilan untuk Penyebaran Penyakit Kolera Berdasarkan Model SIR dengan Vaksinasi. Universitas Negeri Yogyakarta, Yogyakarta.

Lesmana, Murad. 2004. Perkembangan Mutakhir Infeksi Kolera. Universitas Trisakti, Jakarta. 